\title{
PATÊS ELABORADOS A PARTIR DE RESÍDUOS DO BENEFICIAMENTO DE TILÁPIA COM E SEM DEFUMAÇÃO
}

\author{
Marcos Antonio Matiucci* \\ Maria Luiza Rodrigues de Souza* \\ Ana Paula Sartório Chambo ${ }^{* * x}$ \\ Kelly Cristina Vitorino $0^{*+*+x}$ \\ Suzana Réia \\ Rafaela Verdi ${ }^{\star \star *+}$
}

\begin{abstract}
RESUM0: 0 presente trabalho teve como objetivo elaborar patês de aparas de tilápia e farinha de resíduos de tilápia defumada. Foram utilizados três tratamentos e cinco repetições, sendo eles patê com aparas de tilápia (Trat 1), patê com aparas e farinha de carcaça defumada (Trat 2) e patê com aparas e farinha de aparas defumadas (Trat 3). Os tratamentos foram avaliados para sua caracterização microbiológica e para avaliação da composição nutricional e aspectos sensoriais. As análises sensoriais revelaram que o produto foi bem aceito pelos consumidores, indicando que a inclusão das farinhas não interferiu nas características sensórias do patê. A inclusão de farinha de carcaça defumada nos patês de aparas de tilápia aumentou o teor proteico e diminui o teor de carboidrato. Com a inclusão das farinhas nos patês houve a redução do valor calórico nesse produto. Sendo assim a inclusão da farinha de carcaça defumada nos patês de aparas de filetagem da tilápia seria o mais ideal, por apresentar maior teor de proteína e menor teor de carboidrato. As análises microbiológicas indicaram que os produtos estavam aptos para o consumo humano.
\end{abstract}

PALAVRAS-CHAVE: Aparas de filé; corte em "V" do filé; Carcaça; Co-produtos; Resíduos de filetagem.

\section{PATES MADE FROM RESIDUES IN TILAPIA PROCESSING WITH AND WITHOUT SMOKING}

ABSTRACT: Pates were prepared from tilapia shavings and from smoked tilapia flour. Assay comprised three treatments and five replications: pate with tilapia shavings ( $T$ 1); pate with shavings and flour from smoked carcass (T 2) and pate with smoked shavings and flour (T 3). Treatments were evaluated for microbiological characteristics, nutritional composition and sensorial aspects. Sensorial aspects showed that the product was accepted by consumers and indicated that flour inclusion did not interfere in the pate's sensorial factors. The inclusion of smoked carcass flour in pates with tilapia shavings increased protein rates and decreased carbohydrate rates. The inclusion of flour in pates reduced calorie rates in the product. The inclusion of smoked carcass flour in pates with fillet shavings of tilapia proved to be the best due to high protein rates and lower carbohydrate rates. Microbiological analyses showed products were good for human intake.

KEYWORDS: Fillet shavings; V-type cut of fillet; Carcass; Co-products; Fillet residues.

\footnotetext{
Graduando do curso de Zootecnia na Universidade Estadual de Maringá (UEM), Maringá, PR, Brasil. Bolsista PIBIC/CNPq/FA/UEM. E-mail: m.matiucci@hotmail.com.

* Docente do Centro de Ciências Agrárias (CCA) na Universidade Estadual de Maringá (UEM), Maringá, PR, Brasil.

**** Doutora pelo Programa de Pós-graduação em Zootecnia na Universidade Estadual de Maringá (UEM), Maringá, PR, Brasil.

**** Zootecnista, Maringá - PR, Brasil.

Zootecnista, Maringá - PR, Brasil.

Zootecnista. Consultora Técnica. Instituto de Métricas Agropecuárias, Maringá, PR, Brasil.
} 


\section{INTRODUÇÃO}

0 crescimento significativo da aquicultura brasileira e a mudança de perfil do consumidor estão despertando 0 interesse em relação à industrialização de pescado, pois há um crescente aumento nas buscas por alimentos que contenham qualidades nutricionais e praticidade. 0 aumento na produção de pescado tem levado a um problema que é a grande quantidade de resíduos gerados no processamento. No entanto, 0 aproveitamento desses resíduos ainda é muito pequeno (STEFFENS, 1994), sendo cerca de $50 \%$ a $70 \%$ descartada durante 0 processamento em função da espécie de peixe e tipo de corte para comercialização. Por exemplo, na filetagem da tilápia pode chegar a $70 \%$ e normalmente tem sido descartado na unidade de processamento ou subutilizado. Assim, é de grande importância desenvolver formas adequadas de aproveitamento destes resíduos (cabeças, escamas, peles, vísceras, carcaça, e espinhaço após a retirada dos filés), melhorando a eficiência no processo, principalmente na tentativa de um aproveitamento integral do pescado, proporcionando a sustentabilidade econômica no setor. Outro ponto importante é o crescente interesse, principalmente, em função da qualidade nutricional desses resíduos; em especial os ácidos graxos, da série ômega-3, minerais como 0 cálcio, fósforo e ferro (OLIVEIRA et al., 2002), as vitaminas $A, D$, do complexo $B$, em especial $B 12$, e proteínas 0 que 0 torna um produto de alto valor nutricional (VILA NOVA et al., 2005).

Na filetagem da tilápia são geradas toneladas de resíduos que são eliminados no meio ambiente ou aproveitados como farinha ou silagem na alimentação animal. Entretanto, buscam-se formas mais racionais e econômicas para seu uso na alimentação humana. Através da carne mecanicamente separada (CMS) pode-se produzir surimi, nuggets, hambúrgueres, patê, entre outros produtos de maior valor agregado, promovendo assim o destino sustentável deste produto, por ser ecologicamente correto, economicamente viável e socialmente justo, através da maior geração de renda aos produtores e indústria. 0 patê elaborado a partir de resíduos de filetagem pode promover 0 aproveitamento adequado desses resíduos e a diversificação dos produtos oferecidos pelas indústrias de filetagem. Feiden et al. (2007) estudaram a caracterização de patês pasteurizados à base dos peixes: pacu (Piaractus mesopotamicus), jundiá (Rhandia quelen) e tilápia (Oreochromis niloticus) como alternativa para incentivar 0 aumento de consumo de pescado oferecendo novos produtos processados de rápido e fácil preparo. Estes autores concluíram ser viável a produção de patês utilizando a carne mecanicamente separada de tilápia. Portanto, a elaboração de farinha ou concentrado proteico a partir de resíduos de beneficiamento de peixes e sua inclusão em produtos alimentícios comumente consumidos no dia a dia, pode ser uma fonte de alimento alternativo com potencial econômico e aplicação social, uma vez que os resíduos gerados no processamento do pescado são pouco aproveitáveis, no entanto de excelente qualidade nutricional.

Desta forma, objetivou-se elaborar patês a partir de resíduos do beneficiamento de tilápia com e sem defumação e avaliar as características nutricionais, sensoriais e microbiológicas.

\section{MATERIAIS E MÉTODOS}

\subsection{ELABORAÇÃO DAS FARINHAS DE APARAS E CARCAÇAS DEFUMADAS}

As matérias-primas utilizadas para obtenção das farinhas (carcaças e aparas) foram adquiridas na Unidade de Beneficiamento de Rolândia/PR (Empresa Smart Fish). No Laboratório de tecnologia de pescado, localizado na Fazenda Experimental de Iguatemi FEl, pertencente à Universidade Estadual de Maringá - UEM, estes foram preparados para defumação. As matérias-primas foram submetidas a uma salmoura $(10 \%)$ com extrato de alecrim (1\%), proxitane $(0,5 \mathrm{mg} /$ $\mathrm{kg})$ e BHT $(0,5 \mathrm{mg} / \mathrm{kg})$ durante 15 minutos, em seguida foram colocadas em desidratador por $90 \mathrm{~min}$. Decorrido esse período as matérias-primas foram colocadas em defumador pelo método de defumação a quente, cuja 
temperatura iniciou-se a $60^{\circ} \mathrm{C}$ e finalizou-se a $90^{\circ} \mathrm{C}$, pelo período de $02 \mathrm{~h} 30 \mathrm{~min}$. Utilizou-se um defumador de inox com geração de fumaça fora da câmara de defumação. 0 combustível utilizado para produzir a fumaça foi serragem de eucalipto rosa (Eucalyptus globulus) e, para manutenção da temperatura, foi utilizado 0 gás de cozinha. Depois de defumadas foram prensadas (10 toneladas), moídas em moedor de carne, desidratas e novamente moídas em moedor, tipo faca, para obtenção das farinhas (Figura 1).

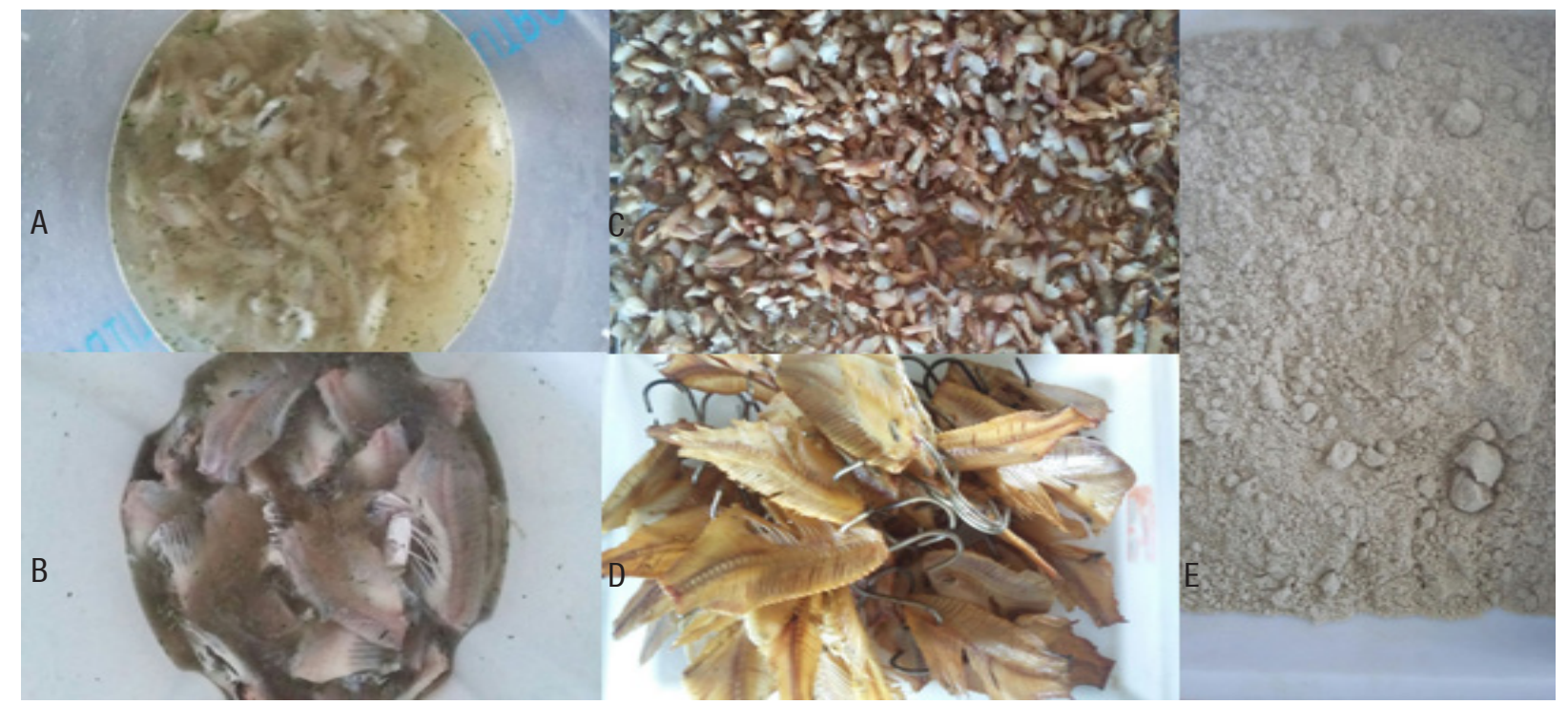

Figura 1. (A) Aparas submetidas a salmoura, (B) Carcaça submetida a salmoura (C) Aparas defumadas, (D) Carcaça defumada, (E) Farinha desidratada e moída.

Fonte: Arquivo Pessoal.

\subsection{ELABORAÇÃO DE PATÊS}

Para elaboração dos patês, as aparas de filetagem de tilápia congeladas foram moídas por cinco vezes para moagem total das espinhas presentes neste tipo de resíduo. As aparas moídas foram pesadas e distribuídas entre os tratamentos. Os patês foram elaborados utilizando a mesma formulação para todos os tratamentos, alterando apenas a inclusão ou não da farinha de peixe (Tabela 1). Para elaboração dos patês foram três tratamentos sendo: 0 Tratamento 1 não inclusão de farinha de peixe, Tratamento 2 com inclusão de farinha de aparas de tilápia defumada e, para o Tratamento 3 a inclusão de farinha de carcaça defumada. 
Tabela 1. Formulação dos patês de aparas com adição de farinha de aparas e carcaça de tilápias defumadas

\begin{tabular}{|c|c|c|c|}
\hline \multirow{3}{*}{ Ingredientes } & \multicolumn{3}{|c|}{ Patês } \\
\hline & Sem farinha & $\begin{array}{c}\text { Aparas } \\
\text { defumadas }\end{array}$ & $\begin{array}{l}\text { Carcaça } \\
\text { defumada }\end{array}$ \\
\hline & \multicolumn{3}{|c|}{ Quantidade (g) } \\
\hline Aparas & 1300,0 & 1200,0 & 1200,0 \\
\hline $\begin{array}{l}\text { Farinha de tilápia } \\
\text { defumada }\end{array}$ & -- & 100,0 & -- \\
\hline $\begin{array}{l}\text { Farinha de aparas } \\
\text { defumadas }\end{array}$ & -- & -- & 100,0 \\
\hline $\begin{array}{l}\text { Gordura } \\
\text { hidrogenada }\end{array}$ & 200,0 & 200,0 & 200,0 \\
\hline Gelo & 150,0 & 150,0 & 150,0 \\
\hline Farinha de aveia & 30,5 & 30,5 & 30,5 \\
\hline $\begin{array}{l}\text { Proteína isolada } \\
\text { de soja }\end{array}$ & 18,0 & 18,0 & 18,0 \\
\hline Sal & 10,0 & 10,0 & 10,0 \\
\hline $\begin{array}{l}\text { Glutamato } \\
\text { monossódico }\end{array}$ & 20,0 & 20,0 & 20,0 \\
\hline Sais de cura & 18,0 & 18,0 & 18,0 \\
\hline Açucar & 0,5 & 0,5 & 0,5 \\
\hline Creme de cebola & 40,0 & 40,0 & 40,0 \\
\hline Suco de limão & 79,0 & 79,0 & 79,0 \\
\hline Condimentos* & 22,0 & 22,0 & 22,0 \\
\hline
\end{tabular}

* cebola em flocos desidratada, pimenta do reino, alho desidratado, cebolinha desidratada, salsinha desidratada e noz moscada.

Para elaboração dos patês foram incluídos os ingredientes de acordo com cada tratamento (Tabela 1), juntamente com as aparas in natura (40\%) e pré-cozidas (60\% do total das aparas) foram homogeneizadas em um multiprocessador até a formação de uma massa homogênea que foram embutidas. Os patês foram identificados, pasteurizados e acondicionados sob refrigeração até a realização das análises de composição química, microbiológica e sensorial. Para a composição química e sensorial os patês elaborados de todos os tratamentos foram armazenados em freezer $\left( \pm 18^{\circ} \mathrm{C}\right)$ até 0 momento da realização das análises (Figura 2). Por tanto, foi realizado a análise microbiológica para avaliar as condições do produto para consumo.

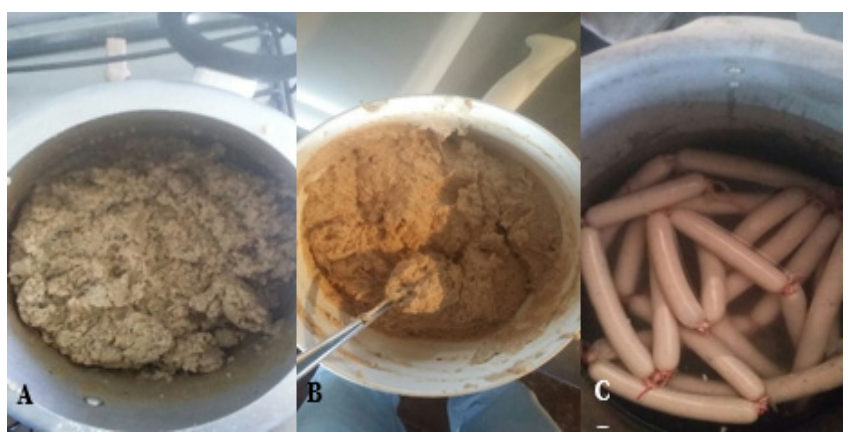

Figura 2. (A) Cozimento. (B) Homogeneização.

(C) Pasteurização.

Fonte: Arquivo Pessoal.

\subsection{ANÁLISE MICROBIOLÓGICA DOS PATÊS}

As análises microbiológicas foram realizadas para o número mais provável (NMP) de coliformes a $35^{\circ} \mathrm{C}$ e $45^{\circ} \mathrm{C}$, contagem de Staphylococcus coagulase positiva em UFC/grama e de Salmonella spp, de acordo com APHA (1992). 0 protocolo microbiológico seguiu os padrões recomendados pela resolução $\mathrm{RDC} \mathrm{n}^{0} 12$, de 2 de janeiro de 2001, da Agência Nacional de Vigilância Sanitária (BRASIL, 2001).

\subsubsection{Análise de composição centesimal e valor calórico das farinhas e dos patês}

Para realização da composição centesimal, os teores de umidade e cinzas foram determinados de acordo com a metodologia da Association of Official Analytical Chemists (AOAC, 2005). Os teores de proteína bruta foram avaliados pelo método de semimicro KjeldahI (SILVA; QUEIROZ, 2002). Os teores de carboidratos foram estimados utilizando-se uma fórmula matemática que considera a soma dos valores de umidade, proteína, lipídeos e cinzas substraídos de 100\% (BRASIL, 2003). 0 valor calórico total foi obtido pela soma da multiplicação dos valores das médias de proteína, lipídios e carboidratos multiplicados pelos fatores 4, 9 e 4, respectivamente (SOUCl et al., 2000). A extração dos lipídios foi realizada segundo adaptação do método citado por Bligh e Dyer (1959) utilizandose uma mistura de clorofórmio, metanol e água em proporção de 2:2:1,8 (v/v/v), respectivamente 


\subsection{ANÁLISE SENSORIAL DOS PATÊS}

As análises sensoriais foram realizadas dez dias após elaboração dos patês, para aguardar os resultados de análises microbiológicas. Foram oferecidas amostras para 50 provadores não treinados. Para a análise sensorial foi fornecida $40 \mathrm{~g}$ de cada amostra em pequenas torradas, juntamente com água para a limpeza das papilas e uma ficha para análise sensorial (Figura 1). Foram avaliados os atributos de aroma, cor, sabor, textura, aparência e aceitação geral de acordo com a escala hedônica de 9 pontos, tendo como os extremos: 1 (desgostei muitíssimo) e 9 (gostei muitíssimo) (MORAES et al., 1993; DUTCOSKY, 2011). Também, foi avaliada a intenção de compra utilizando a escala hedônica de 5 pontos, na qual 5 representa a nota máxima "certamente compraria" 1 representa a nota mínima "certamente não compraria", empregando os procedimentos descritos para análise sensorial por (MEILGAARD et al., 1991; DAMÁSIO; SILVA et al.,1996). 0 índice de aceitação é calculado pela fórmula $I A=$ $A \times 100 / B$, em que $A=$ nota máxima do produto e $B=$ nota mínima da escala (DUTCOSKY, 2011).

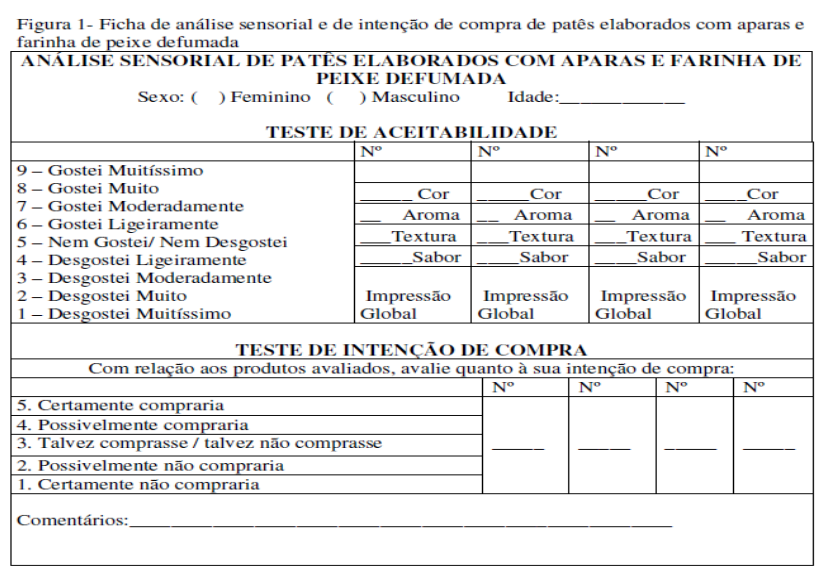

Figura 3. Ficha de análise sensorial e de intenção de compra de patês elaborados com aparas e farinha de peixe defumada

\subsection{DELINEAMENTO EXPERIMENTAL}

0 delineamento experimental utilizado para a análise da composição centesimal e valor calórico dos patês foi inteiramente casualizada com três tratamentos e cinco repetições, cujas médias foram submetidas à análise de variância, e comparadas pelo teste de Tukey, em um nível de $5 \%$ de probabilidade (SAS, 2001).

Para as análises estatísticas dos dados resultantes da análise sensorial $(n=50)$, foi utilizado o sistema computacional SAS, proc GENMOD, considerando a distribuição das variáveis como sendo gamma com função de ligação inversa, em que foi considerado 0 efeito de tratamento e degustadores, testando a inclusão contra 0 controle, por meio de teste de médias e 0 comportamento das notas dos degustadores em função dos diferentes tratamentos utilizados.

\section{RESULTADOS E DISCUSSÃO}

\subsection{ANÁLISE MICROBIOLÓGICA}

As farinhas e os patês elaborados com a inclusão de farinha de aparas e de carcaça de tilápia defumada apresentaram boa qualidade microbiológica (Tabela 2), ou seja, estavam dentro dos padrões microbiológicos estabelecidos pela RDC $\mathrm{n}^{0} 12$, da Agência Nacional de Vigilância Sanitária do Ministério da Saúde (BRASIL, 2001). Para coliformes 0 valor foi $<3$ NMP/g, para Staphylococcus foi $<1 \times 10^{2} \mathrm{UFC} / \mathrm{g}$ e para Salmonella ausente. 
Tabela 2. Análise microbiológica de farinha e de patês com farinha de aparas e carcaças de tilápia defumadas

\begin{tabular}{l|c|c|c|l}
\hline \multirow{2}{*}{ Tratamento } & $\begin{array}{c}\text { Coliformes a } 35^{\circ} \mathrm{C} \\
(\mathrm{NMP} / \mathrm{g})\end{array}$ & $\begin{array}{c}\text { Coliformes a } 45^{\circ} \mathrm{C} \\
(\mathrm{NMP} / \mathrm{g})\end{array}$ & $\begin{array}{c}\text { S. coagulase positiva } \\
(\mathrm{UFC} / \mathrm{g})\end{array}$ & \multicolumn{1}{l}{ Salmonella sp. 25g } \\
\cline { 2 - 5 } & $<3$ & $<3$ & $<10^{2}$ & Ausência \\
\hline Farinhas & $<3$ & $<3$ & $<10^{2}$ & Ausência \\
\hline Carcaças & $<3$ & $<3$ & $<10^{2}$ & Ausência \\
Aparas & $<3$ & $<3$ & $<10^{2}$ & Ausência \\
\hline Patês & $<3$ & $<3$ & $<10^{2}$ & Ausência \\
\hline Sem farinha & $<3$ & \\
Aparas defumadas & $<3$ &
\end{tabular}

$\mathrm{NMP}=$ Números mais provável; UFC= Unidade formadora de colônia.

3.2 COMPOSIÇÃO CENTESIMAL E VALOR CALÓRICO DA FARINHA DE RESÍDUOS DE FILETAGEM DE TILÁPIA DEFUMADA

De acordo com a composição centesimal das farinhas de aparas e de carcaça de tilápia defumada (Tabela 3), pode-se observar que não houve diferença significativa para os valores médios de umidade $\mathrm{e}$ proteína bruta (8,12 e 64,81\%, respectivamente).

0 teor de umidade encontrado para as farinhas de aparas e de carcaça defumadas (Tabela 3) estão de acordo com o Regulamento de Inspeção Industrial e Sanitário de Produtos de Origem Animal (RIISPOA, 1997), que, infere valores inferiores a $12 \%$ de umidade para a segurança desta classe de produtos.

0 teor lipídico foi superior $(p<0,05)$ na farinha de carcaças defumadas em relação à farinha de aparas defumadas. Estes valores de lipídeos podem estar associados ao fato de os resíduos de carcaça serem mais ricos em gordura devido à região ventral apresentar maior teor de gordura, já as aparas são resíduos mais homogêneos e possuem maior quantidade de carne e ossos, o que justifica os dados de cinzas relatados a seguir. Os teores de cinzas variaram de 22,48 a $26,85 \%$, sendo 0 maior valor $(p<0,05)$ referente à farinha de aparas. Como 0 valor calórico está intimamente associado ao teor de lipídios e carboidratos, e considerando que os valores de carboidratos foram irrelevantes nestas amostras, a farinha de carcaça apresentou médias superiores à farinha de aparas para esta variável, uma vez que também possui maior teor lipídico (Tabela 3).
Tabela 3. Composição centesimal e valor calórico de farinha de carcaças e aparas de tilápia defumadas. Dados expressos em média \pm desvio-padrão

\begin{tabular}{|c|c|c|c|c|}
\hline \multirow{2}{*}{$\begin{array}{l}\text { Nutrientes } \\
(\%)\end{array}$} & \multicolumn{2}{|c|}{ Farinha defumada ${ }^{\star \star \star}$} & \multirow{2}{*}{ Valor $\mathrm{P}^{*}$} & \multirow{2}{*}{ CV (\%) } \\
\hline & Carcaça & Aparas & & \\
\hline Umidade & $\begin{array}{c}8,10 \pm \\
0,27 a\end{array}$ & $\begin{array}{c}8,15 \pm \\
0,61 a\end{array}$ & 0,90 & 5,82 \\
\hline $\begin{array}{l}\text { Proteína } \\
\text { Bruta }\end{array}$ & $\begin{array}{c}65,52 \pm \\
2,60 \mathrm{a}\end{array}$ & $\begin{array}{c}64,09 \pm \\
1,53 a\end{array}$ & 0,46 & 3,29 \\
\hline Lipídeos & $\begin{array}{c}9,89 \pm \\
0,45 a\end{array}$ & $\begin{array}{l}8,03 \pm \\
0,85 b\end{array}$ & 0,03 & 7,64 \\
\hline Cinzas & $\begin{array}{c}22,48 \pm \\
1,90 \mathrm{~b}\end{array}$ & $\begin{array}{c}26,85 \pm \\
0,65 a\end{array}$ & 0,02 & 5,76 \\
\hline $\begin{array}{l}\text { Valor } \\
\text { Calórico }{ }^{\star \star}\end{array}$ & $\begin{array}{c}327,09 \pm \\
5,04 \mathrm{a}\end{array}$ & $\begin{array}{c}300,18 \pm \\
6,80 \mathrm{~b}\end{array}$ & $<0,01$ & 1,91 \\
\hline
\end{tabular}

${ }^{*}$ Médias na mesma linha seguidas de letras distintas diferem entre si pelo teste de Tukey a $5 \% .{ }^{*}$ Valor calórico refere-se a $\mathrm{kcal} / 100 \mathrm{~g}$ de amostra. ${ }^{* *}$ Valor de carboidrato inferior a $1 \%$.

A redução do teor de umidade durante 0 processo de elaboração da farinha tende a concentrar os nutrientes, cujos teores foram encontrados em quantidades elevadas, em especial o teor de proteínas e cinzas, nas farinhas de carcaças e aparas, quando comparados com outros alimentos como feijão, arroz, carne bovina e frango (NEPA, 2011).

Os percentuais nutricionais obtidos para as farinhas de carcaça e aparas defumadas corroboram com os valores citados na literatura. Por exemplo, de acordo com Rodrigues et al. (2004), na farinha de pescado são encontrados percentuais de proteína oscilando entre 55 a 70\%. Além das proteínas, a matéria 
graxa concentra-se na faixa de 4 a $8 \%$, minerais de 12 a $33 \%$ e umidade de 6 a $10 \%$.

Reafirmando estes valores, Rocha et al. (2011) citam teores de $2,33 \%$ de umidade, $73,43 \%$ de proteína bruta, 9,67\% de extrato etéreo e $13,77 \%$ de cinza, para farinha de tilápia. Stevanato et al. (2007), ao realizarem um estudo sobre a composição química de farinha de cabeças de tilápias, encontraram também elevados teores de proteína $(38,4 \%)$, cinzas $(19,4 \%)$ e lipídios (35,5\%), Contudo, os valores de proteína e cinzas obtidos por estes autores são menores que os relatados no presente estudo, sendo superado somente pelo teor lipídico, isto porque se trata de matérias-primas com grande distinção, as cabeças de tilápia tendem a ter maior concentração de lipídeos que a carcaça e as aparas.

Ainda neste contexto, e considerando que 0 produto estudado provinha de carcaças e aparas defumadas, pode-se dizer que este produto possui as mesmas características de elevados teores de proteínas, cinzas e lipídeos que as farinhas de resíduos não defumados, cujos valores são similares aos relatados por Godoy (2006) que desenvolveu uma farinha aromatizada a partir de carcaças defumadas de tilápia do Nilo (Oreochromis niloticus) que continha $17,41 \%$ de umidade, $32,51 \%$ de proteína bruta, $19,72 \%$ lipídeos totais e $26,22 \%$ de cinzas.

\subsection{COMPOSIÇÃO CENTESIMAL E VALOR CALÓRICO DE PATÊS DE APARAS ELABORADOS COM FARINHA DE APARAS E FARINHA DE CARCAÇA DEFUMADAS}

As formulações de patês de aparas elaborados com farinha de aparas e farinha de carcaça defumada encontram-se nos padrões estabelecidos pela legislação brasileira para umidade, gordura e proteína, estando em desacordo com a relação ao teor de carboidratos totais para o patê elaborado sem farinha e com farinha de aparas defumadas. De acordo com 0 regulamento que edita a identidade e a qualidade de patês, a umidade, gordura e carboidratos totais máximos devem ser respectivamente de, 70, 32 e $10 \%$. Para o teor proteico o mínimo estabelecido é de 8\% (BRASIL, 2000).

Os patês de aparas elaborados com farinha de aparas e farinha de carcaça defumada de tilápia não apresentaram diferença significativa para a umidade ( $X=52,03 \%)$ e para as cinzas ( $X=2,95 \%)$, entre os tratamentos (Tabela 4). Os maiores teores $(p<0,05)$ de proteína foram encontrados no tratamento com adição de farinha de carcaça defumada (Tabela 4). Este fato, no entanto, não está relacionado à inclusão desta no patê, uma vez que não houve diferença no teor proteico entre as duas farinhas utilizadas (Tabela 3).

0 valor de carboidrato foi superior no patê com a farinha de aparas defumadas $(p<0,05)$. Já 0 teor de lipídeos foi superior $(p<0,05)$ no tratamento sem adição de farinha; 0 que pode ter contribuído para esta diferença é que a inclusão das farinhas de aparas e carcaças, por serem ricas em outros compostos como, proteínas e minerais tenham diluído o teor lipídico dos patês que receberam a inclusão de farinha, possibilitando maior concentração lipídica no patê sem a adição de farinha de peixe (Tabela 4).

Bem como o relatado para as farinhas de aparas e de carcaças, 0 valor calórico dos patês também foi superior $(p<0,05)$ no tratamento com maior teor de lipídeos, que neste caso foi o patê sem adição de farinha (Tabela 4).

Os valores obtidos no presente estudo estão de acordo com os observados por Minozzo et al. (2008) para 0 teor de umidade $(58,03 \%$ e $56,78 \%)$ e cinzas $(3,26 \%$ e $3,01 \%$,). Contudo diferem para os demais atributos, estes autores, ao trabalharem com a utilização de carne mecanicamente separada de tilápia (Oreochromis nicoticus) para a produção de patês cremoso e pastoso obtiveram inferiores aos do presente estudo para proteínas (8,77\% e 9,69\%) e carboidratos $(3,83 \%$ e $2,37 \%$, ) e superiores para 0 teor lipídico $(26,12 \%$ e $28,15 \%)$. Esta mesma diferença pode ser verificada em um outro trabalho realizado por Minozzo et al. (2010) com a avaliação de patê de armado (Pterodoras granulosus), cujos valores referentes à umidade, às cinzas, aos lipídeos, às proteínas e aos carboidratos foram de $61,56 \%, 2,50 \%$, $24,86 \%, 9,84 \%$ e $1,22 \%$, respectivamente.

Corroborando com o presente estudo, Echarte et al. (2004) relataram valores de umidade de $55,44 \%$, $56,06 \%$ e $64,63 \%$, proteínas $7,51 \%, 8,62 \%$ e $7,99 \%$, gordura $26,39 \%, 16,10 \%$ e $13,72 \%$, cinzas $2,37 \%$, 
$5,02 \%$ e $2,54 \%$, carboidratos $8,29 \%, 14,2 \%$ e $11,12 \%$, e valor calórico de $301 \%, 236 \%$ e $200 \% \mathrm{kcal} / \mathrm{kg}$, respectivamente para de salmão, anchova e bacalhau.

Tabela 4. Composição centesimal e valor calórico de patês de aparas de peixe com adição de farinha de aparas e carcaça de tilápia defumadas. Dados expressos em média \pm desvio-padrão

\begin{tabular}{|c|c|c|c|c|c|}
\hline \multirow{2}{*}{ Nutrientes (\%) } & \multicolumn{3}{|c|}{ Patê } & \multirow{2}{*}{ Valor $\mathrm{P}^{*}$} & \multirow{2}{*}{ CV (\%) } \\
\hline & Sem farinha & Aparas defumadas & Carcaça defumada & & \\
\hline Umidade & $52,40 \pm 0,75$ & $52,13 \pm 0,40$ & $51,56 \pm 0,82$ & 0,37 & 1,31 \\
\hline Proteína bruta & $19,89 \pm 0,10 b$ & $19,82 \pm 0,23 b$ & $24,67 \pm 3,44 a$ & 0,46 & 3,29 \\
\hline Lipídeos & $12,40 \pm 0,30 \mathrm{a}$ & $10,46 \pm 0,25 b$ & $10,58 \pm 0,10 b$ & $<0,01$ & 1,64 \\
\hline Cinzas & $2,81 \pm 0,05$ & $2,61 \pm 0,80$ & $3,43 \pm 0,30$ & 0,19 & 16,80 \\
\hline Carboidratos & $12,50 \pm 0,95 a b$ & $14,97 \pm 0,40 \mathrm{a}$ & $9,75 \pm 3,26 b$ & 0,04 & 15,92 \\
\hline Valor calórico** & $241,17 \pm 1,36 a$ & $233,30 \pm 2,1 b$ & $232,95 \pm 3,93 b$ & 0,01 & 1,14 \\
\hline
\end{tabular}

\subsection{ANÁLISE SENSORIAL DE PATÊS DE APARAS ELABORADOS COM FARINHA DE APARAS E FARINHA DE CARCAÇA DEFUMADA}

De acordo com a análise sensorial do patê de aparas pode-se verificar que não houve diferença significativa entre os tratamentos para os atributos avaliados (Tabela 5). Para todos os tratamentos, os atributos de cor, aroma, textura e sabor receberam notas médias superiores a 7,5 indicando boa aceitação do produto. A impressão global do produto também foi avaliada com médias acima de 7,0. De acordo com Dutcosky (2011), estes valores indicam que os provadores "gostaram moderadamente" a "gostaram muito" dos patês, independente da formulação. De acordo com os resultados da análise de intenção de compra os provadores relataram que "possivelmente comprariam" os patês.

Tabela 5. Análise sensorial de patês de aparas de peixe com adição de farinha de aparas e carcaça de tilápia defumadas. Dados expressos em média \pm desvio-padrão

\begin{tabular}{lccccc}
\hline Atributos sensoriais $^{\star *}$ & \multicolumn{3}{c}{ Tratamentos } & Valor P* & CV (\%) \\
\cline { 2 - 4 } Cor & 1 & 2 & 3 & & 23,47 \\
Aroma & $7,48 \pm 1,80$ & $7,42 \pm 1,80$ & $7,54 \pm 1,66$ & 0,94 & 17,93 \\
Textura & $7,60 \pm 1,71$ & $7,94 \pm 1,20$ & $8,00 \pm 1,24$ & 0,31 & 18,70 \\
Sabor & $7,56 \pm 1,74$ & $7,82 \pm 1,24$ & $7,88 \pm 1,32$ & 0,50 & 20,38 \\
Impressão global & $7,62 \pm 1,86$ & $7,98 \pm 1,31$ & $7,82 \pm 1,54$ & 0,53 & 20,66 \\
\hline Intenção de compra*** & $7,40 \pm 1,73$ & $7,62 \pm 1,48$ & $7,78 \pm 1,47$ & 0,47 & 21,41 \\
\hline
\end{tabular}

*teste de Tukey $(\mathrm{p}<0,05) .{ }^{\star \star}$ Escala hedônica 9 pontos. ${ }^{\star \star \star}$ Escala hedônica 5 pontos. 
As médias dos atributos sensoriais obtidas no presente estudo foram superiores as relatadas por Minozzo et al. (2010), que avaliando as formulações de patê de aramado (Pterodoras granulosus), não obtiveram médias superiores a 4,00. Já em relação à aceitação geral do produto, tanto 0 autor supracitado quando Minozzo et al. (2008) em um estudo realizado com patê cremoso com CMS de tilápia, a aceitação geral foi superior a $70 \%$, assim como no presente estudo.

Resultados favoráveis à elaboração de patês à base de peixe, também foram observados por Feiden et al. (2010), ao estudarem a caracterização de patês pasteurizados à base dos peixes: pacu (Piaractus mesopotamicus), jundiá (Rhandia quelen) e tilápia (Oreochromis niloticus) como alternativa para incentivar 0 aumento de consumo de pescado. Bordignon et al. (2006) também encontraram para patês cremoso de tilápia e pacu, padrões de qualidade aceitáveis a excelentes, sendo semelhantes aos valores do teste de perfil de atributos realizados para os patês aparas de tilápia desta pesquisa.

A utilização de resíduos de filetagem para elaboração de produtos como os patês e farinhas para inclusão em alimentos é uma forma inteligente de aproveitamento desses resíduos, impedindo que estes sejam descartados no meio ambiente $\mathrm{e}$ incentivando indiretamente o consumo de pescado. A defumação tende a agregar valor em produtos alimentícios inferindo melhor aceitação pelo mercado, por ser um produto diferenciado. Contudo, no presente estudo não houve preferência pelo produto defumado, demonstrando que ambos seriam igualmente apreciados pelo mercado consumidor.

\section{CONCLUSÕES}

Sabendo-se do potencial das aparas e das carcaças na elaboração produtos alimentícios e a possibilidade de diminuir impacto ambiental com 0 aproveitamento destes resíduos gerado durante os processos de filetagem e corte em $\mathrm{V}$ do filé de tilápia, pode-se conferir maior sustentabilidade ao setor aquícola. Portanto, os patês elaborados e as farinhas de aparas e de carcaças defumadas estavam dentro dos padrões microbiológicos para consumo humano. Os atributos sensoriais revelaram que os patês tiveram boa aceitação pelos consumidores, sendo que a inclusão das farinhas não interferiu nas características organolépticas do produto elaborado. A inclusão de farinha de carcaça defumada nos patês de aparas de tilápia proporcionou maior teor de proteína e menor teor de carboidrato. Com a inclusão das farinhas nos patês houve a redução do valor calórico nesse produto. Desta forma o mais adequado seria incluir a farinha de carcaça defumada nos patês de aparas de filetagem da tilápia por apresentar maior teor de proteína e menor teor de carboidrato.

\section{REFERÊNCIAS}

AOAC - Association Of Afficial Analytical Chemists. Official methods of Analysis of the Association of Analytical Chemistry. 12. ed. Washington, 2005.

APHA - Americam Pubblic Health Association. Compendium of methods for the microbiological examination of foods. 3 . ed. Washington: 15 APHA, 1992.

BLIGH, E. G.; DYER, W. J. A rapid method of total lipid extraction and purification. Can. J. Biochem., v. 37, p. 911-17, 1959.

BORDIGNON, A. C.; BOSCOLO, W. R.; GARBELINI, J.; HAYASHI, H.; WEIRICH, C. E.; FEIDEN, A.; MALUF, M. F. Avaliação microbiológica e sensorial de patê cremoso de filé de tilápia (Oreochromis niloticus) e pacu (Piaractus mesopotamicus) defumados. In: CONGRESSO AQUACIÊNCIA, 4., 2006, Bento Gonçalves. Anais [...]. Aquaciência, 2006.

BRASIL. Agência Nacional de Vigilância Sanitária. Resolução - RDC nº 12 de 02de janeiro de 2001. 
Padrão Microbiológico para Alimentos. Diário Oficial da união. Brasília, 23 dez. de 2001.

BRASIL. Ministério da Agricultura. Departamento de Inspeção de Produtos de Origem Animal.

\section{Regulamento técnico de identidade e qualidade}

de patê. Disponível em: http://www.agricultura.govbr/ sda/dipoa/anexo1_in_21_2000.htm. Acesso em: 25 dez. 2003.

BRASIL. Ministério da Agricultura. Instrução Normativa $\mathrm{n}^{0} 21$, de 31 de julho de 2000. Regulamento técnico para fixação dos padrões de identidade e qualidade para patês. Diário Oficial [da] República Federativa do Brasil, Brasília, DF, 17. jul. 2000. Anexo I.

\section{DAMÁSIO, M.H.; SILVA, M.A.A.P. Curso de}

treinamento em análise sensorial. Apostila Campinas: Fundação Tropical de Tecnologia "André Tosello", 1996.

DUTCOSKY, S.D. Análise sensorial de alimentos. 3. ed. Curitiba: Champagnat, 2011. 426p.

ECHARTE, M.; CONCHILLO, A.; ANSORENA, D.; ASTIASARÁN, I. Evaluation of the nutritional aspects and cholesterol oxidation products of pork liver and fish patés. Food Chemistry, v. 86, n. 1, p. 47-53, 2004.

FEIDEN, A.; BOSCOLO W. R.; DALLAGNO, J. M.; HIGUCHI L. H.; WEIRICH, C. E.; BORDIGNON, A. C. Patê à base de pescado e sua caracterização físicoquímico e sensorial. In: I CONGRESSO BRASILEIRO DE PRODUÇÃO DE PEIXES NATIVOS DE ÁGUA DOCE, 1., 2010. Anais [...]. Disponível em: http://www. cpao.embrapa.br/congressopeixe2007/TRABALHOS/ TECNOLOGIA_E_PROCESSAMENTO_DO_PESCADO/ TECPESC_04.pdf. Acesso em: 06 de Janeiro de 2010.

GODOY, L. C. Farinha de carcaça de peixe com ervas aromáticas para alimentação humana. 2006. 35f. Trabalho de conclusão de curso
(Graduação em Zootecnia) - Universidade Estadual de Maringá, 2006.

NEPA - NÚCLEO DE ESTUDOS E PESQUISAS EM ALIMENTAÇÃO. Tabela brasileira de composição de alimentos. 4. ed. rev. e ampl. Campinas: NEPAUNICAMP, 2011. $161 \mathrm{p}$.

MEILGAARD, M.; CIVILE, G.V.; CARR, B.T. Sensory evaluation techniques. 2. ed. Boca Raton: CRC Press, Inc., 1991.

MINOZZO, M. G. WASZCZYNSKYJ, N. BOSCOLO, W. R. Obtenção de patê de armado (Pterodoras granulosus) e a sua caracterização microbiológica, sensorial e físico-química. Brazilian Journal Food Technology, Campinas, v. 13, n. 3, p. 182-188, 2010.

MINOZZO, M. G.; WASZCZYNSKYJ, N.; BOSCOLO, W. R. Utilização de carne mecanicamente separada de tilápia (Oreochromis niloticus) para a produção de patês cremoso e pastoso. Alimentos \& Nutrição, Araraquara, v. 19, n. 3, p. 315-319, 2008.

MORAES, M. A. C. Métodos para avaliação sensorial dos alimentos. 8. ed. Campinas: UNICAMP, 1993.

OLIVEIRA, M. et al. Avaliação das Farinhas de Peixe e Pena, no Confinamento de Bezerros Leiteiros Desmamados, Através de Dietas Calculadas em Termos de Proteína Bruta ou de Proteína Metabolizável. R. Bras. Zootec., v. 31, n. 3, p. 15711581, 2002

RIISPOA - REGULAMENTO DA INSPEÇÃO INDUSTRIAL E SANITÁRIA DE PRODUTOS DE ORIGEM ANIMAL. Ministério da Agricultura, Pecuária e Abastecimento. Seção II - Derivado do Pescado, Artigo 466. 1997.

ROCHA, J. B. S.; SILVEIRA, C. S.; LEDO, C. A. S.; BARRETO, N. S. E. Composição e estabilidade de farinha de tilápia (Oreochromis niloticus) produzida 
artesanalmente para 0 consumo humano. Magistra, Cruz das Almas, v. 23, n. 4, p. 215-220, 2011.

RODRIGUES, M. S. M.; RODRIGUES, L. B.; CARMO, J. L.; JÚNIOR, W. B. A.; PATEZ, C. Aproveitamento integral do pescado com ênfase na higiene, manuseio, cortes, salga e defumação. In: CONGRESSO BRASILEIRO DE EXTENSÃO UNIVERSITÁRIA, 2., 2004. Belo Horizonte, MG. Anais [...]. Belo Horizonte, 2004.

STATISTICAL ANALYSIS SYSTEM - SAS/STAT user's guide. The GENMOD procedure. 2001.

SILVA, D.J.; QUEIROZ, A.C. Análise de Alimentos: métodos químicos e biológicos. 3. ed. Viçosa, MG: Universidade Federal De Viçosa, 2002. 235 p.

SOUCI, S. W.; FACHMAN, H.; KRAUT, E. Foods

Composition and Nutrition Tables. $6^{\text {th }}$ ed. Medpharm Scientific Publishers, 2000.

STEFFENS, W. Replacing fish meal with poultry byproduct meal in diets for rainbow trout, Oncorhynchus mykiss. Aquaculture, v. 1, n. 124, p. 27-34. 1994.

STEVANATO, F. B.; PETENUCCI, M. E.; MATSUSHITA, M.; MESOMO, M. C.; SOUZA, N. E.; VISENTAINER, J. E. L.; ALMEIDA, V. V.; VISENTAINER, J. V. Avaliação química e sensorial da farinha de resíduo de tilápias na forma de sopa. Ciência e Tecnologia de Alimentos, v. 27, n. 3, p. 567-571, 2007.

VILA NOVA, C. M. V. M.; GODOY, H. T.; ALDRIGUE, M. L. Composição química, teor de colesterol e caracterização dos lipídios totais de tilápia (Oreochromis niloticus) e pargo (Lutjanus purpureus). Ciência e Tecnologia de Alimentos, v. 25, n. 3, p. 430-436, 2005. 